\title{
Induction and Characterization of Fruit Abscission during Early Physiological Fruit Drop in Citrus
}

\author{
Xi Li ${ }^{1}$, Akira Kitajima ${ }^{2 *}$, Tsuyoshi Habu ${ }^{2 * *}$, Keiko Kataoka ${ }^{2 * *}$, Rihito Takisawa ${ }^{2}$ \\ and Tetsuya Nakazaki² \\ ${ }^{1}$ Graduate School of Agriculture, Kyoto University, Kyoto 606-8502, Japan \\ ${ }^{2}$ Experimental Farm, Graduate School of Agriculture, Kyoto University, Kizugawa 619-0218, Japan
}

\begin{abstract}
A new method of inducing fruit abscission by incubating detached ovaries and fruits in agar medium was developed in citrus. Ovary and fruit abscission in the satsuma mandarin, 'Kiyomi', hyuganatsu, and ponkan during early physiological fruit drop was characterized using this method. For primary physiological fruit drop, the abscission of detached ovaries could be divided into three patterns, including an early type in hyuganatsu, a medium type in 'Kiyomi', and a late type in satsuma mandarin and ponkan. The cumulative abscission ratio of four species and cultivars was over $80 \%$ at $96 \mathrm{~h}$ after treatment. However, for secondary physiological fruit drop, the initiation of fruit abscission was earliest in hyuganatsu, and latest in satsuma mandarin. The cumulative abscission ratio was highest in ponkan at $84 \%$ and lowest in hyuganatsu at $6 \%$. The pattern of abscission was different for primary and secondary physiological fruit drop in the four species and cultivars. High temperature promoted the abscission of detached ovaries and fruits in satsuma mandarin and ponkan. Leaf attachment suppressed fruit abscission in 'Kiyomi', hyuganatsu, and ponkan at 7 weeks after anthesis in 2012 and ponkan at 5 weeks after anthesis in 2013. Ovary and fruit abscission in four species and cultivars during early physiological fruit drop was characterized by incubating detached ovaries and fruits in agar medium.
\end{abstract}

Key Words: agar medium, fruit abscission induction, physiological fruit drop.

\section{Introduction}

In citrus, physiological fruit drop is a major problem in commercial fruit production. In general, physiological fruit drop including primary physiological fruit drop and secondary physiological fruit drop affects ovary and young fruit abscission. During primary fruit drop, ovary abscission occurs between peduncle and pedicel. During secondary fruit drop, young fruit drop occurs between fruit and peduncle. Many studies have previously been conducted to elucidate the mechanism un-

Received; February 1, 2016. Accepted; April 13, 2016

First Published Online in J-STAGE on June 15, 2016.

This study was supported by a Grant-in-Aid for Scientific Research (KAKENHI No. 22380025) from the Japan Society for the Promotion of Science (JSPS).

Part of this paper was presented at the 2015 Spring Meeting of the Japanese Horticultural Science.

* Corresponding author (E-mail: kitajima@kais.kyoto-u.ac.jp).

** Present address: Faculty of Agriculture, Ehime University, Matsuyama 790-8566, Japan. derlying physiological fruit drop.

Current evidence indicates that carbohydrate availability when growing young fruits is strongly associated with fruit abscission during physiological fruit drop in citrus (Iglesias et al., 2003). This suggestion has also been advanced for other tree species, such as the persimmon (Kitajima et al., 1990, 1992), peach (Morandi et al., 2008), and grape (Aziz, 2003).

Defoliation reduces the number of leaves (Mehouachi et al., 1995) and shading induces a reduction in photosynthetic activity (Byers et al., 1990), resulting in increased fruit abscission. Girdling treatment reduces fruit abscission by blocking photoassimilate transport from leaves to roots, thus increasing carbohydrate availability for the growing fruits (Yamanishi, 1995). From these results it was concluded that fruit set is highly dependent on carbohydrate availability (Iglesias et al., 2003). All these treatments have been applied to trees. For fruits on trees, the amount of photoassimilate products translocated into sink organs regulates fruit abscission. Fruit abscission is the result of 
competition for carbohydrate between fruits or between growing shoots and fruit. Environmental conditions, such as high temperature, rain, and insufficient light, also increase fruit abscission during physiological fruit drop (Kajiura, 1942; Sato et al., 2010). Regarding the influence of many variables on trees, it is difficult to elucidate the mechanism of fruit abscission during physiological fruit drop.

As a vital hormone regulating plant abscission, ethylene has been investigated for decades. Many studies suggest that ethylene is closely associated with fruit abscission in tree species (Gómez-Cadenas et al., 2000). The plant growth regulators benzylaminopurine (BAP) and aminooxyacetic acid (AOA) have been applied to investigate possible regulation of ethylene biosynthesis and its role in fruit abscission (Dal Cin et al., 2005; Tudela and Primo-Millo, 1992). However, whether the mechanism of fruit abscission induced by ethylene treatment is similar to that in trees during physiological fruit drop or not is not well understood.

To investigate the mechanism of fruit abscission, a new method for induction of fruit abscission could be developed by blocking carbohydrate translocation to the fruit. In the present study, the utility of this method was tested. Using this method, an investigation was undertaken to 1) characterize ovary and fruit abscission in several species and cultivars during primary and secondary physiological fruit drop and 2) determine the effect of temperature and sucrose addition on ovary and fruit abscission.

\section{Materials and Methods}

\section{Plant materials}

'Miyagawa-wase' satsuma mandarin (Citrus unshiu Marcow.), 'Soren tangelo' (C. sp.), 'Kiyomi' (C. unshiu $\times$ C. sinensis (L.) Osbeck), 'Futsukei' hyuganatsu (C. tamurana hort. ex Tanaka), and 'Teishoukei' ponkan (C. reticulata Blanco) were used in these experiments.

\section{Induction of abscission in detached and attached fruit}

Satsuma mandarin and 'Soren tangelo' were used in an experiment performed 6 weeks after anthesis (WAA) in 2011. The trees were grown on the experimental farm of Kyoto University, Osaka, Japan. The experiment was performed with 100 open-pollinated fruits from leafy inflorescence on each cultivar. Of these, 50 fruits were detached from the tree as the "detached fruit" treatment and the remaining 50 were left on the tree as the "attached fruit" treatment. Peduncles of detached fruits were cut $2 \mathrm{~cm}$ from sepals and fruits and were incubated in $1 \%$ agar medium for induction of fruit abscission. For attached fruits, a 1-mm-wide ring was cut with a razor blade around the peduncle $2 \mathrm{~cm}$ from the sepal without reaching the phloem to induce fruit abscission, which resulted in blocking carbohydrate translocation to young fruits. The detached fruits in agar medium were placed beside the tree with the attached fruits outdoors so that the attached fruits and detached fruits were set at a similar temperature condition.

In 2013, the satsuma mandarin, 'Kiyomi', and hyuganatsu were used and the experiment was performed at 6 WAA. Trees were grown on the experimental farm of Kinki University, Wakayama, Japan. Detached and attached fruit treatments were applied as described above.

Abscised fruits were counted every $12 \mathrm{~h}$ after induction of fruit abscission. The cumulative percentage of fruit abscission was calculated as the cumulative number of abscised fruit divided by the total number of fruit.

Abscission of detached ovaries under different conditions during primary physiological fruit drop

Satsuma mandarin, 'Kiyomi', hyuganatsu, and ponkan were used in this experiment in 2012. Trees were grown on the experimental farm of Kinki University. During anthesis, the experiment was performed with 50 ovaries of a single flower on one leafy shoot per species and cultivar. Ovaries were removed at the peduncle $2 \mathrm{~cm}$ from the sepal and were incubated in $1 \%$ agar medium at $25^{\circ} \mathrm{C}$.

In 2011, during anthesis, detached ovaries of satsuma mandarin, hyuganatsu, and ponkan were used. The ovaries were incubated in $1 \%$ agar medium with $0 \%$ sucrose at $15^{\circ} \mathrm{C}$ and $25^{\circ} \mathrm{C}$ or in $1 \%$ agar with $1 \%$ and $3 \%$ sucrose under $25^{\circ} \mathrm{C}$. Numbers of abscised ovaries were recorded every $6 \mathrm{~h}$ after the induction of ovary abscission. The percentage of cumulative ovary abscission was calculated. Fifty detached ovaries were used for each treatment.

Abscission of detached fruit under different conditions during secondary physiological fruit drop

Satsuma mandarin, 'Kiyomi', hyuganatsu, and ponkan were used at 4 WAA in 2012. Trees were grown on the experimental farm of Kinki University. Fifty openpollinated fruits on leafy shoots were detached as described above, and incubated in $1 \%$ agar medium under $25^{\circ} \mathrm{C}$.

Satsuma mandarin, hyuganatsu, and ponkan were used at 5 WAA in 2012. Trees were grown on the experimental farm of Kinki University. One hundred and fifty open-pollinated fruits on leafy shoot were detached as described above and incubated in $1 \%$ agar medium under 20,25 , and $30^{\circ} \mathrm{C}$.

Satsuma mandarin, hyuganatsu, ponkan, and 'Kiyomi' fruits at 7 WAA in 2012 and hyuganatsu and ponkan fruits at 5 WAA in 2013 were used. Trees were grown on the experimental farm of Kinki University. For each species and cultivar, 100 open-pollinated fruits were detached from the peduncle with leaves. Fifty fruits of each treatment with two leaves (leaf attachment) and the fruits with no leaf (leaf detachment) were 
incubated in $1 \%$ agar medium at $25^{\circ} \mathrm{C}$ with a $24 \mathrm{~h}$ light period under about 10000 lux fluorescent lighting.

Abscised young fruits were counted every $6 \mathrm{~h}$ after induction of fruit abscission and the percentage of cumulative fruit abscission was calculated.

\section{Results}

\section{Induction of detached and attached fruit abscission}

Figure 1 shows the abscission patterns of detached and attached satsuma mandarin and 'Soren tangelo' fruits during $186 \mathrm{~h}$ after induction treatment for fruit abscission at 6 WAA in 2011.

For attached fruits, the abscission of 'Soren tangelo' began at $36 \mathrm{~h}$ after induction (HAI) with a $2.9 \%$ cumulative abscission ratio. The cumulative abscission ratio then increased and reached $72.9 \%$ at $186 \mathrm{HAI}$. For attached satsuma mandarin, abscission began at $60 \mathrm{HAI}$ with $0.7 \%$ and the cumulative abscission ratio at 186 HAI reached $21.3 \%$. Initiation of attached fruit abscission in 'Soren tangelo' was earlier and the final abscission ratio was higher than that in satsuma mandarin. The fruit abscission pattern of attached 'Soren tangelo' was different from that of satsuma mandarin. For detached fruits, abscission of 'Soren tangelo' began at 60
HAI and the cumulative abscission ratio increased from $2.9 \%$ to $95.7 \%$ during 186 HAI. For satsuma mandarin, the cumulative abscission ratio was only $6.7 \%$ at 186 HAI. The fruit abscission pattern of detached 'Soren tangelo' was different from that of satsuma mandarin. The abscission pattern of detached fruits was similar to that of attached fruits for 'Soren tangelo' and satsuma mandarin.

Figure 2 shows the abscission patterns of attached and detached fruits in satsuma mandarin, 'Kiyomi', and hyuganatsu during 156 HAI at 6 WAA in 2013.

For detached fruits, the abscission of hyuganatsu began at $72 \mathrm{HAI}$ and the cumulative abscission ratio increased from $10 \%$ to $56 \%$ during $156 \mathrm{HAI}$. The abscission ratio was higher than that of satsuma mandarin and 'Kiyomi'. For satsuma mandarin and 'Kiyomi', fruit abscission began at $108 \mathrm{HAI}$ and $96 \mathrm{HAI}$, respectively, and the cumulative abscission ratios in the two species at $156 \mathrm{HAI}$ were $28 \%$ and $16 \%$, respectively. The fruit abscission pattern was similar for satsuma mandarin and 'Kiyomi', and different for hyuganatsu. The abscission pattern of detached fruits was similar to that of attached fruits for all species and cultivars.
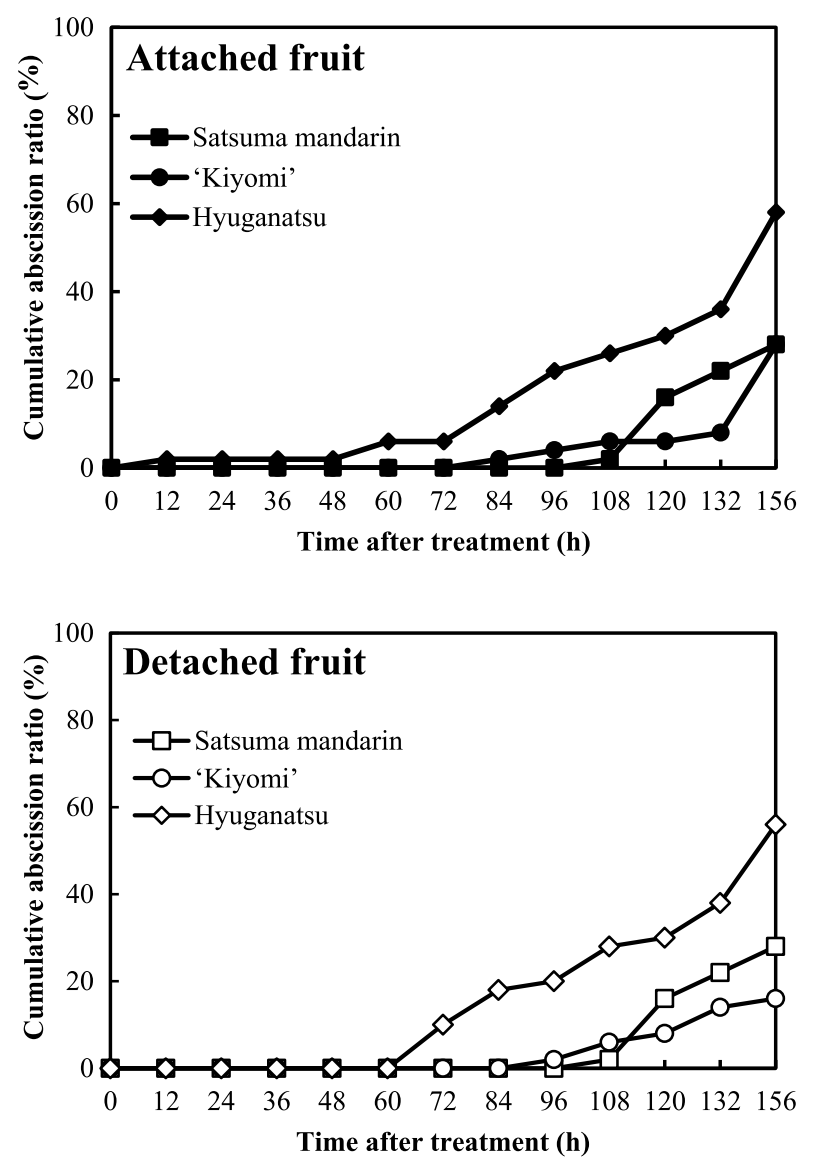

Fig. 2. The abscission patterns of attached and detached fruit in satsuma mandarin, 'Kiyomi', and hyuganatsu during physiological fruit drop at 6 WAA in 2013.
'Soren tangelo' and satsuma mandarin during secondary physiological fruit drop at 6 WAA in 2011.
Fig. 1. The abscission patterns of attached and detached fruit in
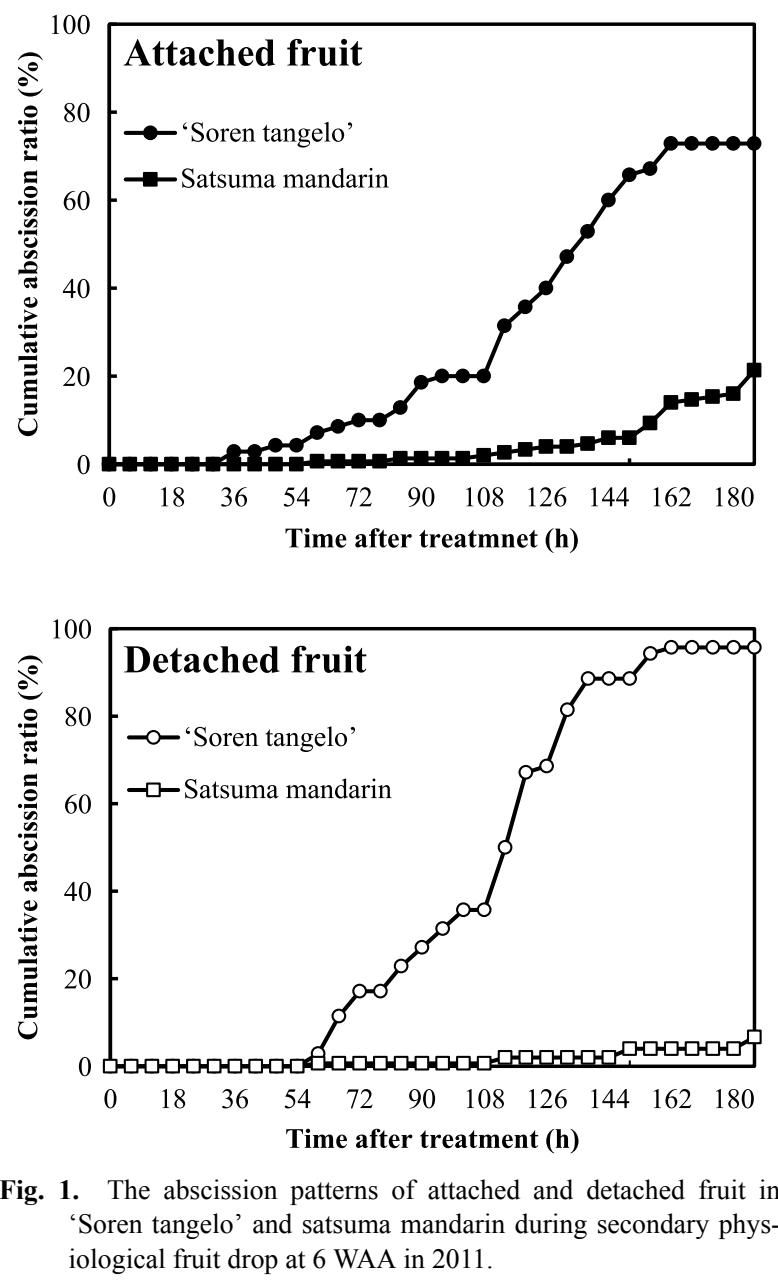
Abscission of detached ovary under different conditions during primary physiological fruit drop

Figure 3 shows the cumulative abscission of detached ovaries in satsuma mandarin, 'Kiyomi', hyuganatsu, and ponkan during $96 \mathrm{HAI}$ at anthesis in 2012. The ovary abscission pattern could be divided into the following three types: (1) an early type in hyuganatsu, with abscission beginning at $12 \mathrm{HAI}$; (2) a medium type in 'Kiyomi', with abscission beginning slightly later than that in hyuganatsu; (3) a late type in satsuma mandarin and ponkan. The initiation of ovary abscission in both species was at 48 HAI. The cumulative abscission ratio of the four species and cultivars at $96 \mathrm{HAI}$ was a little over $80 \%$.

Figure 4 shows the influence of temperature on detached ovary abscission in satsuma mandarin, hyuganatsu, and ponkan at anthesis in 2011. Detached ovaries were incubated in $1 \%$ agar with $0 \%$ sucrose at $15^{\circ} \mathrm{C}$ and $25^{\circ} \mathrm{C}$. Higher temperature promoted the cumulative abscission ratio during $72 \mathrm{HAI}$. In hyuganatsu, the cumulative abscission ratio at $72 \mathrm{HAI}$ was $23.3 \%$ at $15^{\circ} \mathrm{C}$,

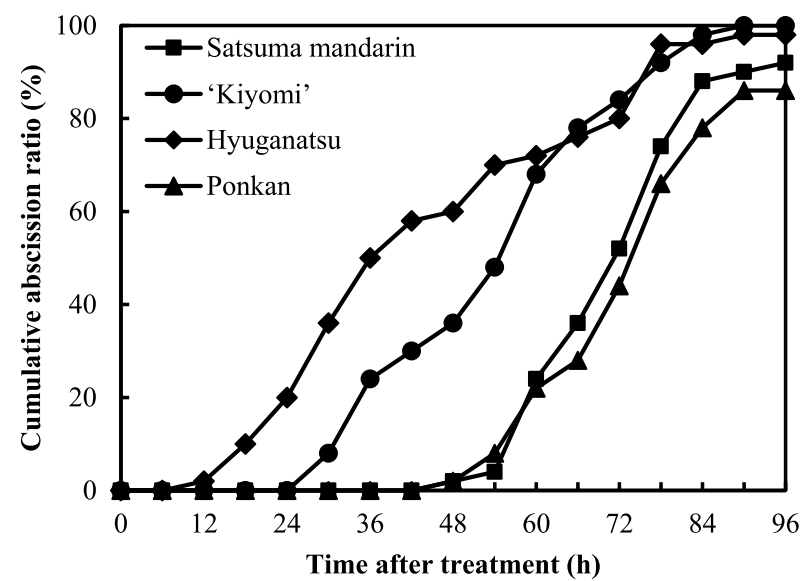

Fig. 3. The ovary abscission pattern at $25^{\circ} \mathrm{C}$ during primary physiological fruit drop in 2012

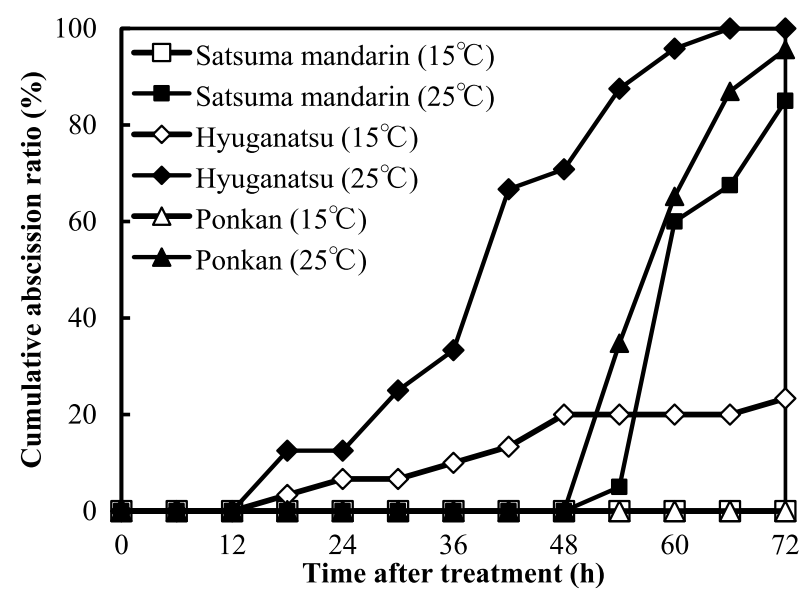

Fig. 4. Effect of temperature on ovary abscission during primary physiological fruit drop in 2011 but reached $100 \%$ at $25^{\circ} \mathrm{C}$. In satsuma mandarin and ponkan, the cumulative abscission ratios at $72 \mathrm{HAI}$ reached $95.7 \%$ and $85 \%$, respectively, at $25^{\circ} \mathrm{C}$, whereas ovary abscission did not occur below $15^{\circ} \mathrm{C}$.

Figure 5 shows the influence of $1 \%$ and 3\% sucrose added to $1 \%$ agar medium on detached ovary abscission in satsuma mandarin, hyuganatsu, and ponkan at anthesis in 2011. In hyuganatsu and ponkan, abscission began at $18 \mathrm{HAI}$ and $54 \mathrm{HAI}$ and the cumulative abscission ratio at 72 HAI was over $90 \%$ under $1 \%$ and $3 \%$ sucrose treatment, similar to that under $0 \%$ sucrose treatment. Sucrose addition did not affect detached ovary abscission of hyuganatsu or ponkan during 72 HAI. However, in satsuma mandarin, $1 \%$ sucrose addition suppressed ovary abscission compared to $0 \%$ and $3 \%$ sucrose addition treatment.

Abscission of detached fruit under different conditions during secondary physiological fruit drop

Figure 6 shows the cumulative abscission ratio of detached fruits in satsuma mandarin, 'Kiyomi', hyuga-

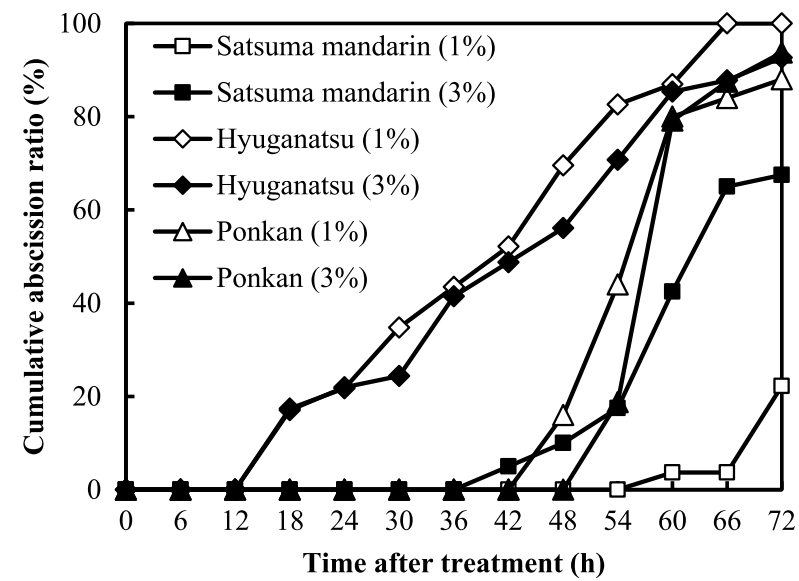

Fig. 5. Effect of sucrose supplementation on ovary abscission at $25^{\circ} \mathrm{C}$ during primary physiological fruit drop in 2011 .

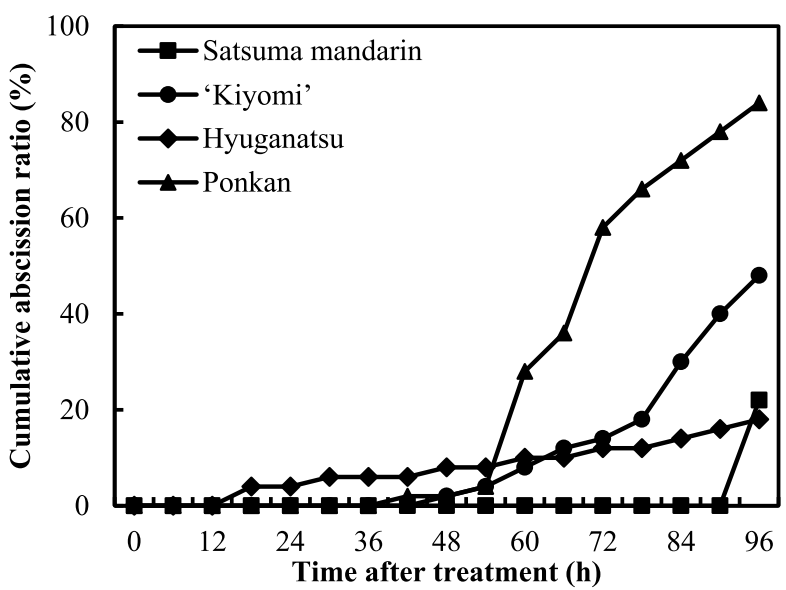

Fig. 6. The fruit abscission pattern during secondary physiological fruit drop at $25^{\circ} \mathrm{C}$ at $4 \mathrm{WAA}$ in 2012 . 
natsu, and ponkan during $96 \mathrm{HAI}$ at 4 WAA in 2012. The fruit abscission of ponkan was initiated at $48 \mathrm{HAI}$ and the cumulative abscission ratio then reached $84 \%$ at 96 HAI. The fruit abscission of 'Kiyomi' began at 48 HAI and the cumulative abscission ratio was $48 \%$ at 96 HAI. The abscission of fruit of hyuganatsu and satsuma mandarin began at $18 \mathrm{HAI}$ and $90 \mathrm{HAI}$, respectively, and the cumulative abscission ratio at 96 HAI was approximately $20 \%$ in both species. The cumulative abscission ratio was highest in ponkan and lowest in hyuganatsu.

Figure 7 shows the effect of different temperatures
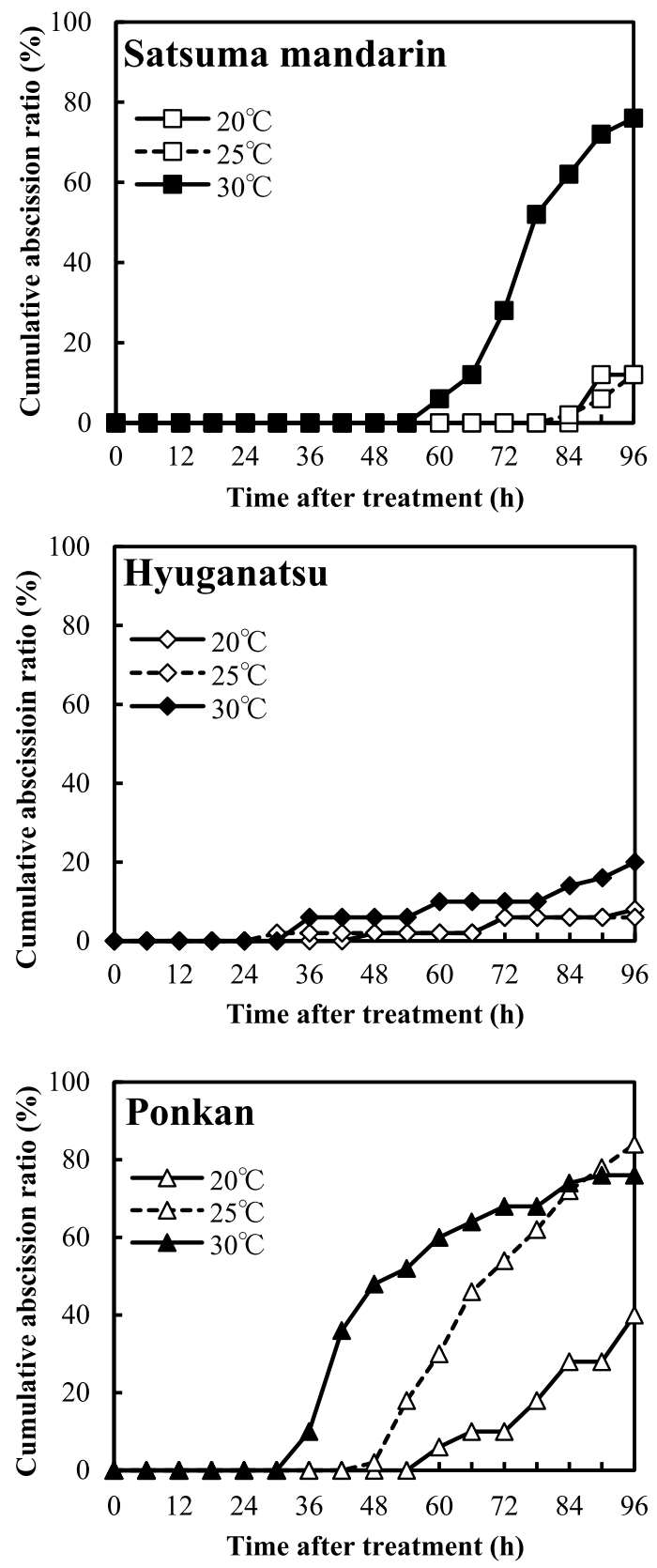

Fig. 7. Effect of temperature on fruit abscission in satsuma mandarin, hyuganatsu, and ponkan during secondary physiological fruit drop at 5 WAA in 2012. on detached fruit abscission in satsuma mandarin, hyuganatsu, and ponkan at 5 WAA in 2012. In ponkan, under the treatments at 25 and $30^{\circ} \mathrm{C}$, abscission began at 36 and $48 \mathrm{~h}$, respectively, and the cumulative abscission ratios at $96 \mathrm{HAI}$ were $76 \%$ and $84 \%$, respectively. Abscission under the $20^{\circ} \mathrm{C}$ treatment began at $60 \mathrm{HAI}$, and the final abscission ratio at 96 HAI was $40 \%$. In hyuganatsu, fruit abscission was low under each temperature treatment. The cumulative abscission ratio under $30^{\circ} \mathrm{C}$ treatment at 96 HAI was only $20 \%$. In satsuma mandarin, fruit abscission was induced under the $30^{\circ} \mathrm{C}$ treatment, and the cumulative abscission ratio at $96 \mathrm{HAI}$ was $76 \%$, whereas that under the $20^{\circ} \mathrm{C}$ and $25^{\circ} \mathrm{C}$ treatments was only $12 \%$ at $96 \mathrm{HAI}$.

Figure 8 shows the influence of detaching fruits with leaves on fruit abscission in satsuma mandarin, 'Kiyomi', hyuganatsu, and ponkan at 7 WAA in 2012, and Figure 9 shows this influence in hyuganatsu and ponkan at 5 WAA in 2013.

At 7 WAA in 2012, in satsuma mandarin, the cumulative abscission ratios of leaf attachment and detachment were $0 \%$ and $4 \%$, respectively, at 96 HAI. In 'Kiyomi', the initiation of fruit abscission in leaf attachment and detachment was at 72 and $66 \mathrm{HAI}$, respectively, and the cumulative abscission ratios at leaf attachment and detachment treatment were $32 \%$ and $74 \%$, respectively, at 96 HAI. Leaf attachment of hyuganatsu and ponkan delayed initiation of abscission, and the cumulative abscission ratios were $32 \%$ and $28 \%$, respectively, at $96 \mathrm{HAI}$.

At 5 WAA in 2013, in ponkan, leaf attachment delayed initiation of fruit abscission, and the final cumulative abscission ratio at $96 \mathrm{HAI}$ was $24.6 \%$, in contrast to leaf detachment, which increased the cumulative abscission ratio to $64 \%$ at $96 \mathrm{HAI}$. However, in hyuganatsu, irrespective of leaf attachment, the abscission pattern was similar and the cumulative abscission ratio was below $20 \%$ during 96 HAI.

\section{Discussion}

The relationship between carbohydrate supplementation and hormonal regulation of citrus fruit abscission during physiological fruit drop has been previously studied (Iglesias et al., 2003, 2006; Roitsch, 1999). Many tree treatments, such as defoliation, shading, and girdling, have been applied to investigate the mechanism of fruit abscission. Defoliation (Mehouachi et al., 1995) and shading (Byers et al., 1990) decreased photosynthetic activity, whereas girdling blocked photoassimilate transport from leaves to roots, thus increasing carbohydrate availability to the growing fruits (Yamanishi, 1995). Sucrose supplementation increased citrus fruit set (Iglesias et al., 2003). These results indicate that fruit set is highly dependent on carbohydrate availability. However, hormones also influence abscission. Exogenous ethylene or plant growth regulators have been applied to investigate fruit abscission in 

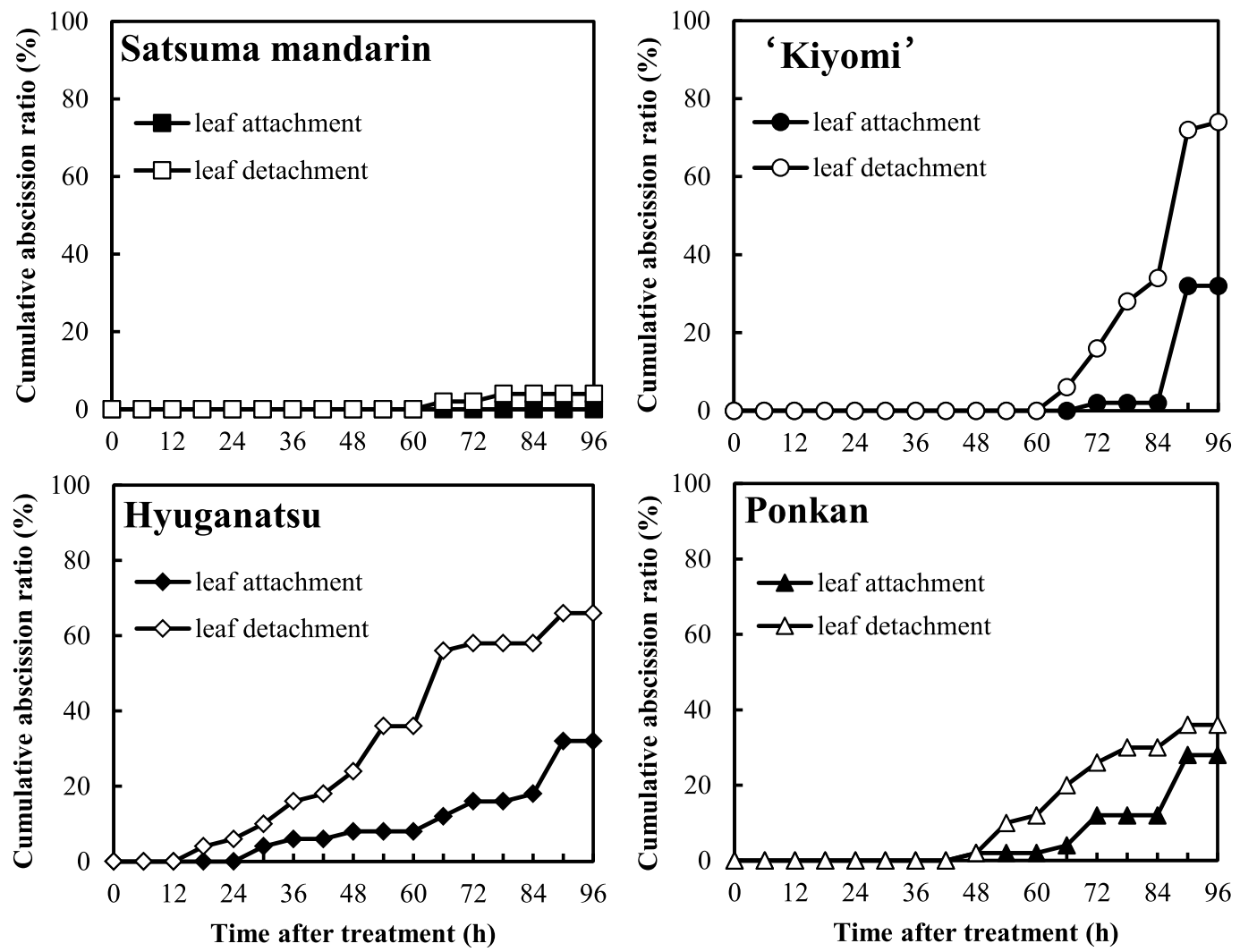

Fig. 8. The pattern of fruit (leaf attachment and leaf detachment) abscission in satsuma mandarin, 'Kiyomi', ponkan, and hyuganatsu at $25^{\circ} \mathrm{C}$ during secondary physiological fruit drop at 7 WAA in 2012.

various fruit trees (Pozo et al., 2004; Untiedt and Blanke, 2001). Carbon shortage induced fruit abscission via ethylene, which was considered as the final hormonal product to induce fruit drop during physiological fruit drop (Gómez-Cadenas et al., 2000). Although these treatments have been commonly applied for investigation of fruit abscission, it is not known whether the mechanism of natural fruit abscission is similar to that in ethylene-induced fruit abscission. Moreover, the occurrence of natural fruit abscission is not very clear under the fruit abscission induction treatments described above because of unstable environmental conditions, such as high temperature, rain, and insufficient light. In our study, a new method, namely incubation of detached fruits in agar medium to exclude variable influences on the tree during physiological fruit drop, was applied. In this experiment, to block carbohydrate translocation to the fruit, peduncle ringing was conducted on attached fruits and incubation in agar medium was conducted on detached fruits. The abscission pattern of detached fruit incubation in agar medium was similar to that of fruits on the tree in satsuma mandarin and 'Soren tangelo' at 6 WAA in 2011 (Fig. 1) and in satsuma mandarin, 'Kiyomi', and hyuganatsu at 6 WAA in 2013 (Fig. 2). These results indicate that a similar mechanism regulates abscission for both detached fruits in agar medium and attached fruits on the tree. De- tached leaf explant incubation has also been performed to investigate the leaf abscission process in citrus (Agustí et al., 2008). We conclude that incubation of detached fruits in agar medium is a useful method for inducing fruit abscission.

In the primary physiological fruit drop, the final 96 HAI cumulative abscission ratio of detached ovaries in four species and cultivars uniformly exceeded $80 \%$ (Fig. 3), although the time of abscission initiation was different for each species and cultivar. However, in the secondary physiological fruit drop, the final $96 \mathrm{HAI}$ cumulative abscission ratio of satsuma mandarin, 'Kiyomi', and hyuganatsu was under $50 \%$, whereas that of ponkan reached $84 \%$ (Fig. 6). Detached ovaries reached a higher abscission ratio during primary physiological fruit drop, whereas detached fruits did not reach abscission ratios as high as detached ovaries during secondary physiological fruit drop. This result indicates that different mechanisms trigger ovary and fruit abscission in the primary and secondary physiological fruit drop stages. In citrus, physiological fruit drop was activated through two abscission zones located between the peduncle and pedicel during primary fruit abscission and between the peduncle and fruit during secondary fruit abscission (Iglesias et al., 2007). 1aminocyclopropane-1-carboxylic acid (ACC) treatment was unable to reactivate the abscission zone between 



Fig. 9. The pattern of fruit (leaf attachment and leaf detachment) abscission in ponkan and hyuganatsu at $25^{\circ} \mathrm{C}$ during secondary physiological fruit drop at 5 WAA in 2013.

peduncle and pedicle or peduncle and fruit after the period of physiological fruit drop (Iglesias et al., 2006), indicating that the mechanisms regulating abscission in the two physiological fruit drops are different. In citrus, the involvement of separation layers in young fruit abscission has rarely been investigated. Further studies are needed to clarify the differences in formation of two abscission zones in citrus.

Plant hormones are among the internal signals promoting abscission. A high level of endogenous gibberellins (GAs) resulted in high fruit set and elevated parthenocarpic ability in satsuma mandarin (Talón et al., 1992). Satsuma mandarin showed the lowest cumulative abscission ratio during 96 HAI among four species and cultivars in secondary physiological fruit drop (Fig. 6). This observation probably results from reduction by GAs in satsuma mandarin fruit abscisison. In citrus, carbohydrate shortage resulted in young fruit abscission by triggering increased levels of ACC (Gómez-Cadenas et al., 2000). The fruit abscission mechanism may depend on the ability of the abscission zone to sense ethylene (Bonghi et al., 2000). Further research on the expression of ethylene biosynthesis and ethylene receptor genes may identify their relationships with fruit abscission in species and cultivars.
Citrus physiological fruit drop has been proposed to depend on temperature. Inoue and Chien (1987) reported that satsuma mandarin grown in sunlit phytotron rooms showed severe fruit abscission under high temperature. Sato et al. (2010) also reported that physiological fruit drop in citrus was promoted by a $2^{\circ} \mathrm{C}$ increase in air temperature after full bloom. These results suggest a close relationship between temperature and fruit abscission. In our experiment, the cumulative abscission ratio of detached ovaries in satsuma mandarin, hyuganatsu, and ponkan was extremely high at $25^{\circ} \mathrm{C}$ compared with that at $15^{\circ} \mathrm{C}$ (Fig. 4), indicating a result similar to previous observations, that is, there is a clear relationship between ovary abscission and temperature in each species and cultivar. In contrast, detached fruit abscission at $30^{\circ} \mathrm{C}$ in hyuganatsu was only slightly induced, whereas that in satsuma mandarin and ponkan was promoted (Fig. 7). However, $25^{\circ} \mathrm{C}$ and $15^{\circ} \mathrm{C}$ treatment did not promote fruit abscission in satsuma mandarin and hyuganatsu. These results suggest that the response of the abscission mechanism to temperature is different in ovaries and fruits or among species and cultivars. It appears that the ovary is much more sensitive to temperature compared with fruit and that each species and cultivar has a different mechanism for responding to the same temperature during fruit abscission.

We investigated the effect of sucrose supplementation on induction of abscission of detached ovaries and fruits. Addition of $1 \%$ and $3 \%$ sucrose in agar medium showed no effect on suppression of ovary abscission in satsuma mandarin, hyuganatsu, or ponkan, except for $1 \%$ sucrose addition for satsuma mandarin (Fig. 5). It appears that ovary abscission may be not affected by carbohydrate supplementation during flowering. Therefore, more investigations are needed to clarify factors affecting induction of ovary abscission during primary physiological fruit drop.

Partial defoliation promoted young fruit abscission and carbohydrate availability was important for fruit abscission (Iglesias et al., 2003). Fruit abscission was suppressed by leaf attachment in hyuganatsu and 'Kiyomi' at 7 WAA, and ponkan at 5 WAA (Figs. 8 and 9), which probably resulted from carbohydrate supplementation from leaves. However, the effects of leaf attachment on suppression of fruit abscission were different in cultivars and times. The signal of fruit abscission induction that related to reduction of photosynthesis transport or changes in plant hormones from leaves may be different in species and cultivars at 7 WAA and 5 WAA. We considered that the difference in the fruit abscission pattern of leaf attachment and detachment in hyuganatsu and ponkan at 7 WAA and 5 WAA could be useful for gene expression analysis to identify fruit abscission induction signals.

Environmental conditions such as high temperature, rain, and insufficient light increased fruit abscission during physiological fruit drop (Kajiura, 1942; Sato 
et al., 2010). However, besides environment conditions, fruit abscission is also influenced by genetic factors. For example, endogenous levels of auxins and GAs are higher in the ovaries of parthenocarpic than in normal tomato lines (Gillaspy et al., 1993). Satsuma mandarin has a high degree of natural parthenocarpy and a high fruit set (Talón et al., 1992). Characterization of fruit abscission in each species and cultivar was difficult for attached fruits in the field. In the present study, the abscission pattern of ovaries and fruits in four species and cultivars during physiological fruit drop was determined using incubation of detached ovaries and fruits in agar medium. Therefore, we propose that detached fruit incubation allows characterization of fruit abscission potential in each species and cultivar during physiological fruit drop.

In this study, abscission of ovaries and fruits in four species and cultivars was characterized by incubation of detached ovaries and fruits in agar medium, and the pattern of abscission differed between primary and secondary physiological fruit drop. Temperature was closely associated with abscission of detached ovaries and fruits. Leaf attachment suppressed abscission of detached fruits.

\section{Acknowledgements}

We would like to thank Dr. M. Fumoro and Dr. N. Tomohiro at Kinki University for providing plant materials and generous technical assistance in this experiment.

\section{Literature Cited}

Agustí, J., P. Merelo, M. Cercós, F. R. Tadeo and M. Talón. 2008. Ethylene induced differential gene expression during abscission of citrus leaves. J. Exp. Bot. 59: 2717-2733.

Aziz, A. 2003. Spermidine and related-metabolic inhibitors modulate sugar and amino acid levels in Vitis vinifera L.: possible relationships with initial fruitlet abscission. J. Exp. Bot. 54: $355-363$.

Bonghi, C., P. Tonutti and A. Ramina. 2000. Biochemical and molecular aspects of fruitlet abscissions. Plant Growth Regul. 31: 35-42.

Byers, R. E., J. A. Barden, R. F. Polomski, R. W. Young and D. H. Carbaugh. 1990. Apple thinning by photosynthetic inhibition. J. Amer. Soc. Hort. Sci. 115: 14-19.

Dal Cin, V., M. Danesin, A. Boschetti, A. Dorigoni and A. Ramina. 2005. Ethylene biosynthesis and perception in apple fruitlet abscission (Malus domestica L. Borch). J. Exp. Bot. 56: 2995-3005.

Gillaspy, G., H. Ben-David and W. Gruissem. 1993. Fruits: a developmental perspective. Plant Cell 5: 1439-1451.

Gómez-Cadenas, A., J. Mehouachi, F. R. Tadeo, E. Primo-Millo and M. Talón. 2000. Hormonal regulation of fruitlet abscission induced by carbohydrate shortage in citrus. Planta 210:
636-643.

Iglesias, D. J., M. Cercós, J. M. Colmenero-Flores, M. A. Naranjo, G. Ríos, E. Carrera, O. Ruiz-Rivero, I. Lliso, R. Morillon, F. R. Tadeo and M. Talón. 2007. Physiology of citrus fruiting. Braz. J. Plant Physiol. 19: 333-362.

Iglesias, D. J., F. R. Tadeo, E. Primo-Millo and M. Talón. 2003. Fruit set dependence on carbohydrate availability in citrus trees. Tree Physiol. 23: 199-204.

Iglesias, D. J., F. R. Tadeo, E. Primo-Millo and M. Talón. 2006. Carbohydrate and ethylene levels related to fruitlet drop through abscission zone A in citrus. Trees 20: 348-355.

Inoue, H. and C. F. Chien. 1987. Effect of different temperatures between day and night on the early fruit drops in satsuma mandarins. J. Agric. Sci., Kagawa Univ. 39: 11-19 (In Japanese with English abstract).

Kajiura, M. 1942. Kaki no seiriraka ni kansuru kenkyu, III. Kou oyobi kanso tono kankei. J. Japan. Soc. Hort. Sci. 13: 1-14 (In Japanese).

Kitajima, A., H. Akuta, T. Yoshioka, T. Entani, M. Nakano and M. Ishida. 1992. Influence of seeded fruit on seedless fruit set in Japanese Persimmon cv. Fuyu (Diospyros kaki L. f.). J. Japan. Soc. Hort. Sci. 61: 499-506.

Kitajima, A., T. Matsumoto, M. Ishida and Y. Sobajima. 1990. Relationship between dry matter production of bearing shoots and physiological fruit drop of Japanese Persimmon, by shading treatments. J. Japan. Soc. Hort. Sci. 59: 75-81.

Mehouachi, J., D. Serna, S. Zaragoza, M. Agustí, M. Talon and E. Primo-Millo. 1995. Defoliation increases fruit abscission and reduces carbohydrate leaves in developing fruits and woody tissues of Citrus unshiu. Plant Sci. 107. 189-197.

Morandi, B., L. C. Grappadelli, M. Rieger and R. Lo Bianco. 2008. Carbohydrate availability affects growth and metabolism in peach fruit. Physiologia Plantarum 133: 229-241.

Pozo, L., R. Yuan, I. Kostenyuk, F. Alferez, G. Y. Zhong and J. K. Burns. 2004. Differential effects of 1-Methylcyclopropene on citrus leaf and mature fruit abscission. J. Amer. Soc. Hort. Sci. 129: 473-478.

Roitsch, T. 1999. Source-sink regulation by sugar and stress. Plant Biol. 2: 198-206.

Sato, K., H. Okuda, M. Iwasaki, Y. Yonemoto, H. Fukamachi and T. Takahara. 2010. Influence of $2^{\circ} \mathrm{C}$ increase under controlled air temperature on physiological fruit drop in citrus. Hort. Res. 9: 159-164 (In Japanese with English abstract).

Talón, M., L. Zacarias and E. Primo-Millo. 1992. Gibberellins and parthenocarpic ability in developing ovaries of seedless mandarins. Plant Physiol. 99: 1575-1581.

Tudela, D. and E. Primo-Millo. 1992. 1-aminocyclopropane-1carboxylic acid transported from roots to shoots promotes leaf abscission in Cleopatra Mandarin (Citrus reshni Hort. ex Tan.) seedlings rehydrated after water stress. Plant Physiol. 100: 131-137.

Untiedt, R. and M. Blanke. 2001. Effect of fruit thinning agents on apple tree canopy photosynthesis and dark respiration. Plant Growth Regul. 35: 1-9.

Yamanishi, O. K. 1995. Trunk strangulation and winter heating effects on fruit size, internal quality and maturation of 'Tosa Buntan' pummelo grown in a plastic house. J. Hort. Sci. 70: $65-74$. 